University of Nebraska - Lincoln

DigitalCommons@University of Nebraska - Lincoln

Sociology Department, Faculty Publications

Sociology, Department of

10-2013

\title{
Accuracy of Within-household Selection in Web and Mail Surveys of the General Population
}

Kristen Olson

University of Nebraska-Lincoln, kolson5@unl.edu

Jolene D. Smyth

University of Nebraska-Lincoln, jsmyth2@unl.edu

Follow this and additional works at: https://digitalcommons.unl.edu/sociologyfacpub

Olson, Kristen and Smyth, Jolene D., "Accuracy of Within-household Selection in Web and Mail Surveys of the General Population" (2013). Sociology Department, Faculty Publications. 233.

https://digitalcommons.unl.edu/sociologyfacpub/233

This Article is brought to you for free and open access by the Sociology, Department of at DigitalCommons@University of Nebraska - Lincoln. It has been accepted for inclusion in Sociology Department, Faculty Publications by an authorized administrator of DigitalCommons@University of Nebraska - Lincoln. 
Published (online ahead of print, October 23, 20I3) in Field Methods,

doi: $10.1177 / 1525822 \times 13507865$

Copyright (C) 2013 Kristen Olson and Jolene D. Smyth; published by Sage Publications.

Used by permission.

\title{
Accuracy of Within-household Selection in Web and Mail Surveys of the General Population
}

\author{
Kristen Olson and Jolene D. Smyth
}

\begin{abstract}
Department of Sociology and Survey Research and Methodology Program, University of Nebraska-Lincoln, Lincoln, NE, USA

Corresponding author: Kristen Olson, 703 Oldfather Hall, Lincoln, NE 68588, USA; email kolson5@unl.edu
\end{abstract}

\begin{abstract}
Household surveys are moving from interviewer-administered modes to self-administered modes for data collection, but many households do not accurately follow within-household selection procedures in mail surveys. In this article, we examine accuracy of within-household selection using an oldest adult/youngest adult method in web, mail, and mixed-mode surveys. The frame for this study comes from a telephone survey conducted with Nebraska residents in which the oldest adult/youngest adult method is used to select the initial respondent. One year later, these telephone participants are followed up using identical household selection methods. This article examines characteristics of people who followed the selection procedures compared to those who did not.
\end{abstract}

Keywords: mixed-mode surveys, web surveys, mail surveys, withinhousehold selection, coverage error 
Obtaining a probability sample of adults living in households requires selecting a probability sample of households and then randomly selecting a person within each household. Methods for sampling persons within households are well established for interviewer-administered surveys, including obtaining a household roster and selecting one person from the roster, selecting the individual with the next or last birthday, or selections based on the number of persons in the household (see review in Gaziano 2005). Yet data are increasingly being collected from the general population using mail and web modes (e.g., Couper and Miller 2008; de Leeuw 2005). Methods for selecting persons within households for self-administered surveys remain relatively unexplored and focus on mail, rather than web, surveys. This article addresses this gap.

With any within-household selection procedure, the wrong household member can be selected, resulting in a coverage error (Groves 1989). Interviewers can help reduce such errors by following the required procedures to select the correct participant. Rates of inaccurate selection with telephone interviewers range from less than $5 \%$ to about $20 \%$ and vary by gender, education, the number of adults in the household, and the salience of birthdates relative to the interview date (Gaziano 2005; Lavrakas et al. 2000; Lind et al. 2000; O'Rourke and Blair 1983; Troldahl and Carter 1964). In self-administered surveys, there is no interviewer present to guide the process of within-household selection, so household members must follow the selection procedures themselves. The few within-household selection studies in mail surveys find that error rates range from about $15 \%$ to over $30 \%$, increase systematically with household size, and vary by gender (Battaglia et al. 2008; Gallagher et al. 1999; Reich et al. 1986; Schnell et al. 2007).

This article empirically evaluates the accuracy of selections made using one within-household selection procedure-an oldest/youngest male/ female selection method - not previously examined in self-administered surveys. We hypothesize that confusion and concealment will affect accuracy of within-household selections. Furthermore, the selection of any given household member may reflect a strong motivation or commitment on the part of that household member to complete the questionnaire or a lack of motivation on the part of other household members.

Confusion during household selection may come from two sources. First, there may be confusion over who qualifies as a member of the household, especially for those with nontraditional household structures (e.g., extended family, boarders), tenuous household ties, or high mobility (Bates and Gerber 1994; Martin 1999, 2007). Second, there may be confusion when respondents do not understand the task itself or have diffi- 
culty recalling and processing information important to completing the task (Martin and Dillman 2008). For example, persons with lower education may have difficulty interpreting the selection instructions or the selection instructions may be too complex.

Concealment may also be a factor in inaccurate within-household selection. Research has shown that concealment of household members, especially young black males, occurs when there is participation in illegal activities, when undocumented immigrants are in the household, or when household members have financial obligations to others (Tourangeau et al. 1997; Valentine and Valentine 1971). Whether these factors also lead to errors in within-household selection is unknown. Additionally, fear of crime, or, more recently, identity theft, may lead some to misreport or refuse to provide identifying personal characteristics (Kim et al. 2011; Malhotra et al. 2004; Phelps et al. 2000).

Errors in within-household selection may also be due to household roles or individual commitment to complete a questionnaire. For example, some people may be the "mail openers" of the household (Battaglia et al. 2008; Schnell 2007). Still others may simply want to be the survey participant (Battaglia et al. 2008; Forsman 1993; O'Rourke and Blair 1983), may be more comfortable completing a self-administered survey, or may find doing so enjoyable.

\section{Data Description}

The data for this study come from two surveys. The first is the 2008 Nebraska Annual Social Indicators Survey (NASIS), a listed random digit dial (RDD) sample of 1,811 adults aged 19 and older (American Association for Public Opinion Research Response Rate 3 [AAPOR RR3] = 38\%). In this survey's within-household selection procedure, for single-adult households, the telephone answerer was selected to participate as the oldest adult. In two-adult households, interviewers randomly selected the youngest or oldest adult in the household. In larger households, the oldest or youngest adult or an adult other than the youngest or oldest adult was randomly selected (e.g., "second oldest adult").

An independent follow-up survey of NASIS respondents who stated their willingness to be included in future social research projects and provided adequate mailing addresses was conducted in 2009. In this study, the Quality of Life in a Changing Nebraska survey (QLCN), households were randomly assigned to one of four self-administered mode conditions (mail only, web only, web with mail follow-up, and mail with web follow-up) and sent one of two questionnaire forms, identical in content 
Table I. Sample Allocation to Oldest and Youngest Adult Assignments, Overall and by Household Size, QLCN.

\begin{tabular}{|c|c|c|c|c|c|c|}
\hline & \multicolumn{2}{|c|}{ Oldest Adult } & \multicolumn{2}{|c|}{ Youngest Adult } & \multicolumn{2}{|c|}{$\begin{array}{l}\text { Second Oldest } \\
\text { (Youngest) Adult }\end{array}$} \\
\hline & $\begin{array}{r}\text { Full } \\
\text { Sample }\end{array}$ & $\begin{array}{r}\text { Respon- } \\
\text { dents }\end{array}$ & $\begin{array}{r}\text { Full } \\
\text { Sample }\end{array}$ & $\begin{array}{r}\text { Respon- } \\
\text { dents }\end{array}$ & $\begin{array}{r}\text { Full } \\
\text { Sample }\end{array}$ & $\begin{array}{r}\text { Respon- } \\
\text { dents }\end{array}$ \\
\hline Overall & 744 & 344 & 430 & 200 & 55 & 21 \\
\hline I adult $\mathrm{HH}$ & 298 & 133 & $\mathrm{n} / \mathrm{a}$ & $\mathrm{n} / \mathrm{a}$ & $\mathrm{n} / \mathrm{a}$ & $\mathrm{n} / \mathrm{a}$ \\
\hline 2 adult $\mathrm{HH}$ & 415 & 197 & 406 & 194 & $\mathrm{n} / \mathrm{a}$ & $\mathrm{n} / \mathrm{a}$ \\
\hline $3+$ adult $\mathrm{HH}$ & 31 & 14 & 24 & 6 & 55 & 21 \\
\hline
\end{tabular}

"n/a" indicates households of this size were not eligible for this condition. The cover letter stated: "To make sure we hear from all different types of Nebraskans, please share this letter with the <oldest/youngest> adult (age 19+) <sex> in the household and have them complete the enclosed questionnaire."

but varying in visual design features (AAPOR RR2 $=46 \%, n=1,229$ full sample, $n=565$ respondents; see Olson et al. 2012 for details). This article focuses on accuracy of within-household selection in the QLCN, which used identical age position language as the NASIS (e.g., youngest, second oldest, oldest) and sex to identify the relevant individual (Table 1).

\section{Method}

Since names and household rosters were not collected in either questionnaire, we do not have a direct measure of accuracy of selection in the QLCN. As a proxy, we measure whether the characteristics of persons who participated in the NASIS match those who participated in the QLCN. Mismatches in characteristics across the two surveys are taken as evidence of inaccurate selection.

The rate of mismatches on sex, year of birth, education, and ethnicity between the QLCN and NASIS are 4.4\% (Hispanic/not Hispanic ethnicity), $7.1 \%$ (sex), $13.1 \%$ (year of birth), and $27.8 \%$ (education). These variables were used to create an indicator of inaccurate selection. The inaccuracy measure uses matches on sex, year of birth, education level, and ethnicity, but permitted an accurate selection to be assigned if one item had missing data and all of the other reported characteristics matched. It also permitted education levels to differ across the two reports by up to one additional year of education in the QLCN, an amount that could 
have been obtained in the time between the two surveys. This leaves $17.9 \%$ of respondents $(n=101)$ defined as inaccurately selected. We conducted all analyses with two other measures of accurate selection (exact match on all four characteristics, with missing counted as mismatch, and match on only age and sex) and found no meaningful differences in our results (available on request).

\section{Measuring Confusion, Concealment, and Commitment}

We use four proxy measures for confusion. First, households with more adults in a household should find the selection task more confusing than smaller households, thus increasing the likelihood of selecting the wrong person. Second, children in the household can create confusion when they are close to the age of majority. Education is the third proxy for confusion, as low education indicates a greater risk of misunderstanding the directions (Couper and Rowe 1996). Finally, we include the selection task itself to which the household was assigned, hypothesizing that selecting the second oldest adult is more confusing than selecting the oldest or youngest adult.

Concealment is measured through age, race, sex, income, concern about identity theft, and fear of crime. Age, sex, and race are included because underreporting of young black males is often attributed to concealment (Tourangeau et al. 1997). We use income and an income item missing data indicator because poorer households may be more likely to misreport the presence of certain household members out of fear of losing benefits, and households that fail to report income may be likely to conceal other information. Finally, general fears over crime and specific concerns about identity theft may cause some to conceal or misreport identifying characteristics, leading to inaccurate selections.

Commitment to the task of being a survey respondent is measured through preferences for particular modes. We hypothesize that preferences for certain survey modes may affect accurate selection among household members. We have four measures of mode preference, asking "If you got a request to do another survey like this one, which of the following types would you be most likely to agree to participate in?" " . . . find the most convenient to participate in?" " . . . be most comfortable answering questions?" and " . . find most enjoyable when answering questions?" We combine face-to-face, home phone, and cell phone preferences into an interviewer- administered preference category and mail and web into a self-administered preference category. We hypothesize that persons who prefer to participate or feel more comfortable participating in a self-administered mode will be more likely to be accu- 
rately selected in a mail or web survey. These four items are highly correlated (Spearman's $\rho>.7, p<.0001$ ). We also hypothesize that people who are more likely to be mail openers or answerers (e.g., females) are more likely to self-select for a self-administered survey than those who are not mail openers.

\section{Alternative Explanations for Inaccurate Selection}

Two additional hypotheses - inaccurate reporting of the number of persons in the household and changes in household composition - arise as explanations for inaccurate selection. First, a mismatch between reporters in the QLCN and NASIS may occur because of inaccurate selection in the NASIS. The number of adults in the household was collected twice during the NASIS. At the beginning of the telephone survey, participants were asked, "To make sure our study is scientific, can you tell me how many adults ages 19 and older are living in your household?" The same question was asked during the middle of the survey: "Including yourself, how many adults age 19 and older live in your household?" We examine discrepancies between reports to these two questions as one indicator of problematic within-household selection in the NASIS that may lead to the appearance of inaccurate selections in the QLCN.

Since the QLCN was conducted one year after the NASIS, we also examine evidence of change in three household characteristics between the two surveys - the number of adults in the household, reports of marital status, and the presence of children. Differences in these characteristics could reflect changes in composition of the same household (e.g., the original respondent gets married) or changes in the whole household (e.g., the entire household moves).

\section{Analysis Methods}

We start with bivariate analyses to examine whether the QLCN study design features of mode and questionnaire form, our proxies for confusion, concealment and commitment, measures of inconsistencies in reports of number of adults in the NASIS, and change in household composition between surveys are associated with inaccurate selections in the QLCN. Then, we evaluate whether the bivariate associations hold in multivariate logistic regression models. We focus on characteristics as reported in the NASIS, that is, characteristics of the person we were attempting to select to participate in the QLCN (QLCN respondent characteristic results available on request). 
Table 2. Logistic Regression Coefficients and Standard Errors for Two Models Predicting Inaccurate Selection of Household Respondent, Target Characteristics Used as Predictors.

\begin{tabular}{|c|c|c|c|c|}
\hline & \multicolumn{2}{|c|}{ Model I $(n=565)$} & \multicolumn{2}{|c|}{ Model $2(n=565)$} \\
\hline & Coefficient & $S E$ & Coefficient & $S E$ \\
\hline Intercept & $-2.606 * * * *$ & 0.738 & $-2.417 * *$ & 0.770 \\
\hline \multicolumn{5}{|l|}{ Confusion measures } \\
\hline I adult/oldest adult & - & - & - & \\
\hline 2 adults /oldest adult & 0.472 & 0.398 & 0.540 & 0.420 \\
\hline 2 adults/youngest adult & 0.607 & 0.369 & 0.611 & 0.397 \\
\hline $3+$ adults/oldest adult & $1.365^{*}$ & 0.678 & $1.360+$ & 0.756 \\
\hline $3+$ adults/second adult & $2.244 * * * *$ & 0.559 & $1.977 * *$ & 0.617 \\
\hline $3+$ adults/youngest adult & 0.704 & 1.213 & 0.482 & 1.260 \\
\hline HS or Less vs. More than HS (ref.) & 0.056 & 0.268 & -0.078 & 0.288 \\
\hline Kids in $\mathrm{HH}$ vs. No Kids (ref.) & $0.47 I+$ & 0.259 & 0.158 & 0.288 \\
\hline \multicolumn{5}{|l|}{ Concealment measures } \\
\hline Female vs. male (ref.) & -0.078 & 0.269 & -0.023 & 0.285 \\
\hline Age in years & - & - & - & - \\
\hline Nonwhite vs. white (ref.) & 0.693 & 0.515 & 0.519 & 0.560 \\
\hline$<\$ 20 \mathrm{~K}$ & - & - & - & - \\
\hline$\$ 20 \mathrm{~K}-\$ 39 \mathrm{~K}$ & -0.123 & 0.550 & -0.199 & 0.578 \\
\hline$\$ 40 \mathrm{~K}-\$ 75 \mathrm{~K} / \$ 80 \mathrm{~K}$ & -0.346 & 0.557 & -0.543 & 0.588 \\
\hline$\$ 75 \mathrm{~K}+/ \$ 80 \mathrm{~K}+$ & -0.420 & 0.576 & -0.517 & 0.606 \\
\hline Income missing & -0.532 & 0.628 & -0.800 & 0.670 \\
\hline $\begin{array}{l}\text { Concern over ID theft } \\
(I=\text { never, } 5=\text { almost always })\end{array}$ & $0.299 *$ & 0.130 & $0.238+$ & 0.138 \\
\hline$\leq$ Median in fear of crime & - & - & - & - \\
\hline$>$ Median in fear of crime & -0.262 & 0.382 & -0.413 & 0.401 \\
\hline Crime questions not asked & 0.240 & 0.293 & 0.051 & 0.308 \\
\hline \multicolumn{5}{|l|}{ Commitment measure } \\
\hline $\begin{array}{l}\text { Mode comfort: Interviewer- } \\
\text { administered questionnaires }\end{array}$ & - & - & - & - \\
\hline $\begin{array}{l}\text { Mode comfort: Self-administered } \\
\text { questionnaires }\end{array}$ & $-0.576^{*}$ & 0.249 & $-0.514+$ & 0.265 \\
\hline Mode comfort: Missing & -0.257 & 0.837 & -0.394 & 0.940 \\
\hline \multicolumn{5}{|l|}{ Study design control variables } \\
\hline Mail only & - & - & - & - \\
\hline Mail web & 0.078 & 0.304 & 0.099 & 0.323 \\
\hline Web mail & -0.256 & 0.315 & -0.263 & 0.340 \\
\hline Web only & -0.017 & 0.379 & 0.035 & 0.405 \\
\hline Form B vs. Form A. (ref.) & -0.134 & 0.235 & -0.144 & $\begin{array}{l}0.254 \\
\text { (continued) }\end{array}$ \\
\hline
\end{tabular}


Table 2. (continued)

\begin{tabular}{|c|c|c|c|c|}
\hline & \multicolumn{2}{|c|}{ Model I $(n=565)$} & \multicolumn{2}{|c|}{ Model $2(n=565)$} \\
\hline & Coefficient & SE & Coefficient & $S E$ \\
\hline \multicolumn{5}{|l|}{ Change in household composition } \\
\hline NASIS only: Different reports \# adults & & & -0.031 & 0.527 \\
\hline \multicolumn{5}{|l|}{ vs. Same reports (ref.) } \\
\hline$\#$ adults in NASIS < \# adults in QLCN & & & $1.113 *$ & 0.443 \\
\hline$\#$ adults in NASIS = \# adults in QLCN & & & - & - \\
\hline \# adults in NASIS > \# adults in QLCN & & & $0.06 \mathrm{I}$ & 0.340 \\
\hline \# adults in QLCN missing & & & $-0.44 \mathrm{I}$ & 1.302 \\
\hline Change in marital status & & & $1.938 * * * *$ & 0.408 \\
\hline Change in presence of kids & & & 0.629 & 0.457 \\
\hline Likelihood ratio test & $39.56^{*}$ & & $82.82 * * * *$ & \\
\hline Pseudo- $R^{2}$ & $7.46 \%$ & & $15.61 \%$ & \\
\hline Area under ROC curve & 0.6784 & & 0.7413 & \\
\hline
\end{tabular}

$+p<.10 ; * p<.05 ; * * p<.01 ; * * * p<.001 ; * * * *<.0001$

All covariates came from the NASIS.

\section{Findings}

Table 2 presents the results from the multivariate analyses. Model 1 is the model with the confusion, concealment, and commitment predictors and model 2 adds covariates for changes in household composition. Some of the covariates are highly correlated. We exclude marital status and age in the multivariate analyses due to high correlations with other variables in the model. Models estimated including age are virtually identical to those reported here, with the coefficient for the presence of children in the household differing between the two models (results available on request).

\section{Study Characteristics}

We expect and find no relationship between inaccurate within-household selection and the study characteristics of mode and questionnaire version. In the mail-only condition, $18.1 \%$ of persons were inaccurately selected, compared to $20.4 \%$ in the mail-then-web condition, $14.4 \%$ in the web-then- mail condition, and $20.3 \%$ in the web-only condition ( $p=$ .49). Accuracy of selection also does not vary over the two questionnaire forms $(18.7 \%$ version $\mathrm{A}$ vs. $17.1 \%$ version $\mathrm{B}, p=.61)$. This lack of association holds in multivariate analyses. 


\section{Confusion}

We expect and find a relationship between the selection criteria (oldest adult, second oldest/youngest adult, and youngest adult) and accuracy of within-household selection. The wrong person was selected in $15.7 \%$ of the households in the "oldest adult" treatment, 18\% in the "youngest adult" treatment, and 52.4\% in the "second oldest/youngest adult" treatment $(p<.0001)$. Inaccurate selection also increases with household size $-12 \%$ of one-adult households, $17.4 \%$ of two-adult households, and $41.5 \%$ of three or more adult households selected the wrong person $(p<.0001)$.

When we examine the selection rule and the number of adults in the household simultaneously, we see that larger households make more errors, especially when they receive the more complex selection criterion (i.e., second oldest/youngest). This holds in multivariate models (Table 2: $3+$ adults/oldest adult selection $b=1.360, p<.10 ; 3+$ adults / second adult selection $b=1.977, p<.01$, model 2). Respondents in households with children at home were selected inaccurately $22.6 \%$ of the time, compared to $15.7 \%$ of the time in households without children $(p<.05)$. This association holds in multivariate analyses $(b=.476, p=.06$, model 1$)$; however, this coefficient is not statistically different from zero once changes in household composition are taken into account (model 2). There is no clear relationship between marital status or education and inaccurate selection $(p>.10)$.

\section{Concealment}

Nonwhite adults are about twice as likely as white adults to have an inaccurate selection $(33.3 \%$ vs. $17.3 \%, p<.10)$, but this does not hold in multivariate models. There is a steady increase in inaccurate selections as concern about identity theft increases $(p<.10)$, a finding that is confirmed in multivariate analyses $(b=0.238, p<.10)$. The other concealment measures, including income, sex, age (in bivariate analyses), and fear of crime are not associated with accuracy of within-household selection $(p>.10)$.

\section{Commitment}

Approximately $20 \%$ of all respondents who prefer interviewer-administered modes or find them more convenient, more comfortable, or 
more enjoyable inaccurately select a respondent, compared to about $15 \%$ of those who prefer self-administered modes. Convenience and comfort are statistically significant in bivariate analyses $(p<.05)$. In the multivariate models, comfort with self-administered questionnaires decreases the probability of inaccurate within-household selection $(b=$ $-.514, p<.10)$.

\section{Errors in Telephone Household Composition}

The reports of the number of adults in the household obtained at the beginning and middle of the NASIS do not match for about $6 \%$ of adults, even though they were asked only about 10 minutes apart. Households in which the respondent gave inconsistent reports in the NASIS were not significantly more likely to make inaccurate respondent selections in the QLCN $(24.3 \%$ vs. $17.4 \%, p=.2)$, a finding that holds in multivariate models.

\section{Change in Household Composition}

Our results indicate that some households may have had a change in household composition between the two surveys. About $24 \%$ of QLCN reports of the number of people in the household did not match reports from the NASIS; $6.5 \%$ of NASIS reports were lower and $17.6 \%$ were higher than the QLCN reports. The other household characteristics marital status and presence of children-failed to match between the two surveys for roughly 7\% of the QLCN respondents.

Changes in reports of marital status, the presence of children, and the number of adults in the household are highly associated with inaccurate selection in both bivariate and multivariate analyses. For example, among households whose marital status was the same in the two surveys, $14 \%$ of respondents were inaccurately selected, compared to $65 \%$ in households whose marital status changed $(p<.0001$; Table 2 : $b=1.938, p<.0001)$. When the number of adults reported is higher in the QLCN than the NASIS, $44 \%$ of the respondents were inaccurately selected compared to $14 \%$ when the reports were identical, and $23.5 \%$ when the QLCN report was less than the NASIS report $(p<.0001$; Table $2: b=1.113, p<.05)$. Among those who failed to report the number of adults in the QLCN, $11 \%$ of persons were inaccurately selected. A similar pattern was observed for changes in the presence or absence of children $(16 \%$ vs. $42 \%, p<.0001)$, although there is no relationship in the multivariate analyses. 


\section{Discussion}

In self-administered surveys, random selection of persons within households is necessary to maintain a probability sample of adults. This study is the first to examine accuracy of within-household selection in both mail and web modes. In this study, about $82 \%$ of the households selected the correct respondent, while about $18 \%$ did not. Our results extend previous research conducted in interviewer-administered surveys to show that there are multiple mechanisms underlying inaccurate selections in mail and web surveys. These mechanisms include that household members may become confused about what they are supposed to do or about who should be considered eligible for participation and that some household members may conceal information about their household. We also expand on previous research by demonstrating that commitment to the survey task through mode preferences also affects accuracy of selection. We find no evidence of differences in accuracy of selection across two single self-administered mode and two mixed-mode conditions.

This study has limitations. The survey from which accuracy of within-household selection was determined was sent to a sample of households that had already participated in a survey in the previous year and had expressed a willingness to participate in additional research. Another limitation is that the frame for the NASIS was listed landline households, excluding cell phone-only households, likely contributing to the absence of young adults in the initial respondent pool (Blumberg et al. 2011). Additionally, although we find that changes in reports of household composition predict inaccurate selections, we cannot determine whether the entire household or members in the same household changed. Despite these limitations, this frame permitted examination of whether the same respondent was selected over two surveys, 1 year apart, conducted by two different modes. It also allowed measurement of a wide variety of characteristics separately from the within-household selection process.

Future research should more closely examine how confusion, concealment, and commitment are related to the decision-making process of opening the mail (or email), reading the selection instructions, accurately making a selection, and convincing the selected respondent to participate, as well as other factors. Confusion and concealment clearly require reading the selection instructions and attempting to make the selection, whereas commitment likely affects the participation decision itself. It is also possible that certain survey topics make confusion, concealment, and commitment concerns in within-household selection more prominent (e.g., income surveys may increase concealment concerns). Unfor- 
tunately, in most general population surveys, we do not have information on confusion, concealment, and commitment before contacting the household. As such, survey practitioners should develop materials that minimize confusion and concealment concerns in the respondent task itself and increase commitment.

Our findings suggest that we need to improve how we communicate selection instructions. More households made errors when given complex selection instructions (i.e., when selecting someone other than the oldest or the youngest adult), something not previously examined. Second, our findings regarding identity theft suggest that methods to convey the legitimacy and trustworthiness of the survey may further increase accurate selections or accurate reporting of personal characteristics. Future research should evaluate the efficacy of traditional confidentiality assurances (and other stronger language) in mitigating the association between identity theft concerns and inaccurate selections. Finally, the mode preference findings suggest that persons who feel more comfortable with self-administered modes may be more likely to follow within-household selection instructions than those who prefer interviewer-administered surveys. Although appeals to the scientific validity of results may resonate with some persons, others may not find such appeals convincing or the instructions may simply be to be too hard to follow. As we increasingly use self-administered questionnaires to conduct large-scale population studies, convincing householders of the importance of accurately selecting a person within their household is more critical than ever.

Acknowledgments - The authors thank the UNL Bureau of Sociological Research for access to the NASIS data, Heather Wood for assistance in collecting the QLCN data, and three anonymous reviewers from Field Methods for helpful comments. An earlier version of this article was presented at the American Association for Public Opinion Research annual meeting, May 2011, Phoenix, Arizona. Funding for this study came from the University of Nebraska-Lincoln Office of Research Layman Fund award. The authors have no potential conflicts of interest with respect to the research, authorship, and/or publication of this article.

\section{References}

Bates, N., and E. Gerber. 1994. A typology of temporary mobility patterns and reporting of usual residence. Proceedings of the American Statistical Association, Survey Research Methods Section 17:331-36.

Battaglia, M. P., M. W. Link, M. R. Frankel, L. Osborn, and A. H. Mokdad. 2008. An evaluation of respondent selection methods for household mail surveys. Public Opinion Quarterly 72:459-69. 
Blumberg, S. J., J. V. Luke, N. Ganesh, M. E. Davern, M. H. Boudreaux, and K. Soderberg. 2011. Wireless substitution: State-level estimates from the National Health Interview Survey, January 2007-June 2010. National Health Statistics Reports, No. 39, National Center for Health Statistics, Hyattsville, MD.

Couper, M. P., and P. V. Miller. 2008. Web survey methods. Public Opinion Quarterly 72:831-35.

Couper, M. P., and B. Rowe. 1996. Evaluation of a computer-assisted self-interview component in a computer-assisted personal interview survey. Public Opinion Quarterly 60:89-105.

de Leeuw, E. 2005. To mix or not to mix data collection modes in surveys. Journal of Official Statistics 21:233-55.

Forsman, G. 1993. Sampling individuals within households in telephone surveys. Proceedings of the American Statistical Association, Survey Research Methods Section 16:1113-18.

Gallagher, P. M., F. J. Fowler, Jr, and V. L. Stringfellow. 1999. Respondent selection by mail obtaining probability samples of health plan enrollees. Medical Care 37: MS50-58.

Gaziano, C. 2005. Comparative analysis of within-household respondent selection techniques. Public Opinion Quarterly 69:124-57.

Groves, R. M. 1989. Survey errors and survey costs. New York: John Wiley.

Kim, J., C. Gershenson, P. Glaser, and T. W. Smith. 2011. The polls-trends: Trends in surveys on surveys. Public Opinion Quarterly 75:165-91.

Lavrakas, P. J., E. A. Stasny, and B. Harpuder. 2000. A further investigation of the last-birthday respondent selection method and within-unit coverage error. Proceedings the American Statistical Association, Survey Research Methods Section 23:890-95.

Lind, K., M. Link, and R. Oldendick. 2000. A comparison of the accuracy of the last birthday versus the next birthday methods for random selection of household respondents. Proceedings of the American Statistical Association, Survey Research Methods Section 23:887-89.

Malhotra, N. K., S. K. Sung, and J. Agarwal. 2004. Internet users' information privacy concerns (IUIPC): The construct, the scale, and a causal model. Information Systems Research 15:336-55.

Martin, E. 1999. Who knows who lives here: Within-household disagreements as a source of survey coverage error. Public Opinion Quarterly 63:220-36.

Martin, E. 2007. Strength of attachment: Survey coverage of people with tenuous ties to residences. Demography 44:427-40. 
Martin, E., and D. A. Dillman. 2008. Does a final coverage check identify and reduce census coverage errors? Journal of Official Statistics 24:571-89.

Olson, K., J. D. Smyth, and H. Wood. 2012. Does giving people their preferred mode actually increase survey participation rates? Public Opinion Quarterly 76:611-35.

O'Rourke, D., and J. Blair. 1983. Improving random respondent selection in telephone surveys. Journal of Marketing Research 20:428-32.

Phelps, J., G. Nowak, and E. Ferrell. 2000. Privacy concerns and consumer willingness to provide personal information. Journal of Public Policy $\mathcal{E}$ Marketing 19: 27-41.

Reich, J., W. Yates, and R. Woolson. 1986. Kish method for mail survey respondent selection. American Journal of Public Health 76:206.

Schnell, R., S. Ziniel, and E. Coutts. 2007. Inaccuracy of birthday respondent selection methods in mail and telephone surveys. Presentation at the European Survey Research Association Conference, June 29, Prague.

Tourangeau, R., G. Shapiro, A. Kearney, and L. Ernst. 1997. Who lives here? Survey undercoverage and household roster questions. Journal of Official Statistics 13:1-18.

Troldahl, V. C., and R. E. Carter. 1964. Random selection of respondents within households in phone surveys. Journal of Marketing Research 1:71-76.

Valentine, C. A., and B. L. Valentine. 1971. A comparative methodological study of under-enumeration and related problems. Washington, DC: U.S. Census Bureau 